\title{
Reduced medication use and improved pulmonary function with supplements containing vegetable and fruit concentrate, fish oil and probiotics in asthmatic school children: a randomised controlled trial
}

\author{
Shu-Chen Lee ${ }^{1,2}$, Yao-Hsu Yang ${ }^{3}$, Shao-Yuan Chuang ${ }^{2}$, Shih-Yi Huang ${ }^{4}$ and Wen-Harn Pan ${ }^{1,2,5 *}$ \\ ${ }^{1}$ Department of Biochemical Science and Technology, College of Life Science, National Taiwan University, \\ Taipei, Taiwan, ROC \\ ${ }^{2}$ Division of Preventive Medicine and Health Services Research, Institute of Population Health Sciences, \\ National Health Research Institutes, Miaoli, Taiwan, ROC \\ ${ }^{3}$ Department of Pediatrics, National Taiwan University Hospital, College of Medicine, National Taiwan University, \\ Taipei, Taiwan, ROC \\ ${ }^{4}$ Department of Nutrition, School of Nutrition and Health Science, Taipei Medical University, Taipei, Taiwan, ROC \\ ${ }^{5}$ Institute of Biomedical Science, Academia Sinica, Taipei, Taiwan, ROC
}

(Submitted 14 March 2012 - Final revision received 30 July 2012 - Accepted 14 September 2012 - First published online 5 December 2012)

\section{Abstract}

Dietary pattern changes may be one of the key factors associated with increasing asthma prevalence. Observational studies have found negative associations between fruit, vegetable and fish consumption and risk of asthma. Experimental studies have also shown that probiotics can modulate the immune system. However, each dietary component exhibits a modest effect. The objective of the present study was to investigate the joint effect of multiple beneficial dietary components on asthma. We designed a 16-week school-based double-blind placebo-controlled randomised trial. The supplement group received fruit plus vegetable concentrate, fish oil and probiotics (FVFP supplement), while the control group received placebos. A total of 192 asthmatic children aged 10-12 years were recruited from elementary schools in metropolitan Taipei. Pulmonary function, medication usage, Paediatric Asthma Quality of Life Questionnaire (PAQLQ) score and the Childhood Asthma Control Test score were evaluated at baseline, and at weeks 8 and 16. Compared with the placebo group, the supplement group showed significant improvement in pulmonary function parameters $(91 v .178 \mathrm{ml}$ for forced vital capacity (FVC), $40 v .107 \mathrm{ml}$ for forced expiratory volume in $1 \mathrm{~s}\left(\mathrm{FEV}_{1}\right)$ and $1.6 v .4 .8 \%$ for $\mathrm{FEV}_{1}: \mathrm{FVC}$ ratio; all $P$ values $\left.<0 \cdot 01\right)$ and had a significantly reduced proportion of those using short-acting inhaled bronchodilators and inhaled corticosteroids. However, the PAQLQ score and the Childhood Asthma Control Test score were not significantly different between the two groups, possibly because the majority of the children were treated routinely. FVFP supplements reduced medication use and improved pulmonary function in asthmatic children. The present study supports an adjuvant intervention with a combination of fruit, vegetable, fish and probiotic foods.

Key words: Asthma: Fruits and vegetables: Fish oil: Probiotics: Children

The prevalence of asthma in school children has rapidly increased over the past few decades, both worldwide and in Taiwan. Dietary pattern changes may be one of the contributing factors ${ }^{(1)}$. Observational studies have shown that intake of vitamin E, vitamin C, carotenoids, Se, polyphenols, vegetables, fruit and n-3 PUFA are negatively associated with asthma, while that of $n$-6 PUFA is positively associated with asthma $^{(1,2)}$. However, supplementation with antioxidants or $n-3$ PUFA alone in adults with asthma has either modest or no clinical benefits ${ }^{(1,3)}$. The Dietary Approach to Stop
Hypertension trial, an unprecedented study that combined multiple beneficial food components, demonstrated a significant and medication-equivalent effect on blood pressure reduction in hypertensive patients ${ }^{(4)}$. Therefore, we intended to adopt this combinatorial principle to examine the effect of multiple beneficial food factors on asthma control, using food concentrate to increase the feasibility.

A fruit plus vegetable concentrate, high in antioxidants, was used in the present study. A previous study has shown that fruit plus vegetable concentrate supplementation can

Abbreviations: CACT, Childhood Asthma Control Test; $\mathrm{FEV}_{1}$, forced expiratory volume in $1 \mathrm{~s}$; FVC, forced vital capacity; FVFP supplement, 'fruit and veggie' capsules, 'fish oil' capsules and 'probiotic' capsules; ICS, inhaled corticosteroids; ORAC, Oxygen Radical Antioxidant Capacity; PAQLQ, Paediatric Asthma Quality of Life Questionnaire. 
increase plasma antioxidant levels and reduce CHD risk factors ${ }^{(5,6)}$. As reactive oxygen species play a key role in inflammatory initiation and amplification in asthmatic airways ${ }^{(7)}$, supplementing fruit plus vegetable concentrate may dampen or prevent the inflammatory response in asthma by restoring the oxidant-antioxidant balance or through other potential mechanisms.

Fish oil is rich in EPA and DHA, which can inhibit cyclooxygenase and lipo-oxygenase enzyme activity, and decrease 2-series $\mathrm{PGE}_{2}$ and 4-series leukotrienes (leukotriene $\mathrm{E}_{4}$, leukotriene $\left.\mathrm{B}_{4}\right)$. The 2 -series $\mathrm{PG}$ have an immunomodulatory function, which modifies the activity of macrophages and lymphocytes and suppresses the production of T-helper 1 (Th1)-related cytokines, promoting the expression of the T-helper 2 (Th2) phenotype associated with asthma. The 4-series leukotrienes have pro-inflammatory properties and are important mediators in the production of airway obstruction $^{(8)}$. Fish oil supplementation reduces the concentration of inflammatory mediators $\left(\mathrm{PGE}_{2}\right.$, leukotriene $\mathrm{E}_{4}$ and leukotriene $\mathrm{B}_{4}$ ), eosinophils and TNF- $\alpha^{(9-11)}$. However, the beneficial effects on forced expiratory volume in $1 \mathrm{~s}\left(\mathrm{FEV}_{1}\right)$, bronchial challenge tests, asthma symptoms and medication use have not been consistent ${ }^{(9-13)}$. This is possibly due to the varied dosage and duration of the fish oil treatment.

The immunomodulatory effects of several probiotics have already been confirmed. Dendritic cells appear central to directing the beneficial immune system effects of probiotic bacteria, and in translating microbial signals from the innate to the adaptive immune system. Regulatory $\mathrm{T}$ cells are also emerging as potentially key players in probiotic-mediated responses ${ }^{(14)}$. Recent clinical trials have shown that supplementation with Lactobacillus gasseri ${ }^{(15)}$ and Bifidobacterium breve ${ }^{(16)}$ significantly improves pulmonary function and significantly reduces systemic production of Th2 cytokines in asthma patients. Therefore, supplementation with probiotics could potentially be of benefit to asthma control. The present study used Lactobacillus salivarius as the probiotic supplement. This particular probiotic has been shown to decrease allergen-induced airway hyperresponsiveness and elevate levels of interferon- $\gamma$ in animal models ${ }^{(17)}$

The aim of the present study was to investigate the combined effects of fruit plus vegetable concentrate, fish oil and probiotic supplements on asthma, related parameters and medication use.

\section{Methods}

The present study is a 16-week, double-blind, randomised, placebo-controlled trial in school children with asthma that tests the efficacy of combining the following supplements: two 'fruit and vegetable' capsules, three to five 'fish oil' capsules and two 'probiotic' capsules per d (FVFP supplement). The present study was conducted according to the guidelines laid down in the Declaration of Helsinki, and all procedures involving human subjects/patients were approved by the institutional review board of Academia Sinica, Taiwan. The trial was registered in clinicaltrials.gov: NCT01366222. Written informed consent was obtained from all the subjects/patients.

\section{Study participants}

Participants who had ever been diagnosed with asthma were recruited from twenty-three elementary schools in metropolitan Taipei through parent conferences. All potential children and their parents had to sign the informed consent form before further eligibility screening was carried out by a paediatrician specialised in asthma. The inclusion criteria of the present trial were as follows: (1) age between 10 and 12 years and (2) with mildly or moderately persistent asthma based on the Global Initiative for Asthma guidelines. The exclusion criteria were as follows: (1) participation in other therapeutic studies in the previous 6 months; (2) regular use of oral corticosteroids, high-dose multivitamin supplements, fish oil supplements or probiotic supplements within 3 months before screening; (3) coagulation disorders or other serious illness; (4) inability to swallow capsules; (5) a resting $\mathrm{FEV}_{1}$ less than 1 litre and (6) being a vegetarian.

\section{Dietary supplement design and preparation}

The FVFP supplement includes three kinds of dietary supplements. Each 'fruit and vegetable' capsule contained a $400 \mathrm{mg}$ concentrate derived from grapes, plums, blueberries, raspberries, cranberries, cherries, cowberries, strawberries, artichokes, beets, carrots, broccoli, white cauliflower, kale, celery, spinach and tomatoes (Schiff Nutrition Group, Inc.). Each capsule contained 986 Oxygen Radical Antioxidant Capacity (ORAC) units, according to Brunswick Laboratory data, which is equal to approximately two servings of fruits and vegetables. One serving of fruits or vegetables contains 350 ORAC units ${ }^{(18)}$. Each 'fish oil' capsule $(500 \mathrm{mg} /$ capsule) contained $230 \mathrm{mg}$ of EPA and $125 \mathrm{mg}$ of DHA (DSM Nutritional Products Limited). The number of fish oil capsules given to individual children was determined according to their body weight: three capsules per $\mathrm{d}$ for those weighing $24 \cdot 8-32 \cdot 6 \mathrm{~kg}$, four capsules for those weighing $34-41.4 \mathrm{~kg}$ and five capsules for those weighing $45 \cdot 3-59 \cdot 2 \mathrm{~kg}$. The daily dosage of EPA plus DHA was $1065-1775 \mathrm{mg}$, which is equal to $1-1.5$ servings of $n$-3-rich oily fish. Each 'probiotic' capsule (1000 mg/capsule) contained $2 \times 10^{9}$ colony-forming units of L. salivarius PM-A0006 (ProMD Biotech Company, Limited).

The placebo capsules were indistinguishable in appearance from the supplement capsules. 'Fruit and vegetable' placebo capsules ( $400 \mathrm{mg} / \mathrm{capsule}$ ) were composed of maize starch (Nihon Shokuhin Kako Company, Limited) and had 79 ORAC units. 'Fish oil' placebo capsules contained $500 \mathrm{mg}$ of maize oil, which was rich in 58\% n-6 PUFA (God-bene Company, Limited). 'Probiotic' placebo capsules (1000 mg/capsule) were composed of yogurt-flavoured maize starch without L. salivarius (ProMD Biotech Company, Limited).

\section{Intervention}

All 197 eligible participants were given placebo capsules during the 2-week run-in period. Of the 197 children, five dropped out of the trial due to personal reasons. The remaining 192 children were randomly assigned to either the 


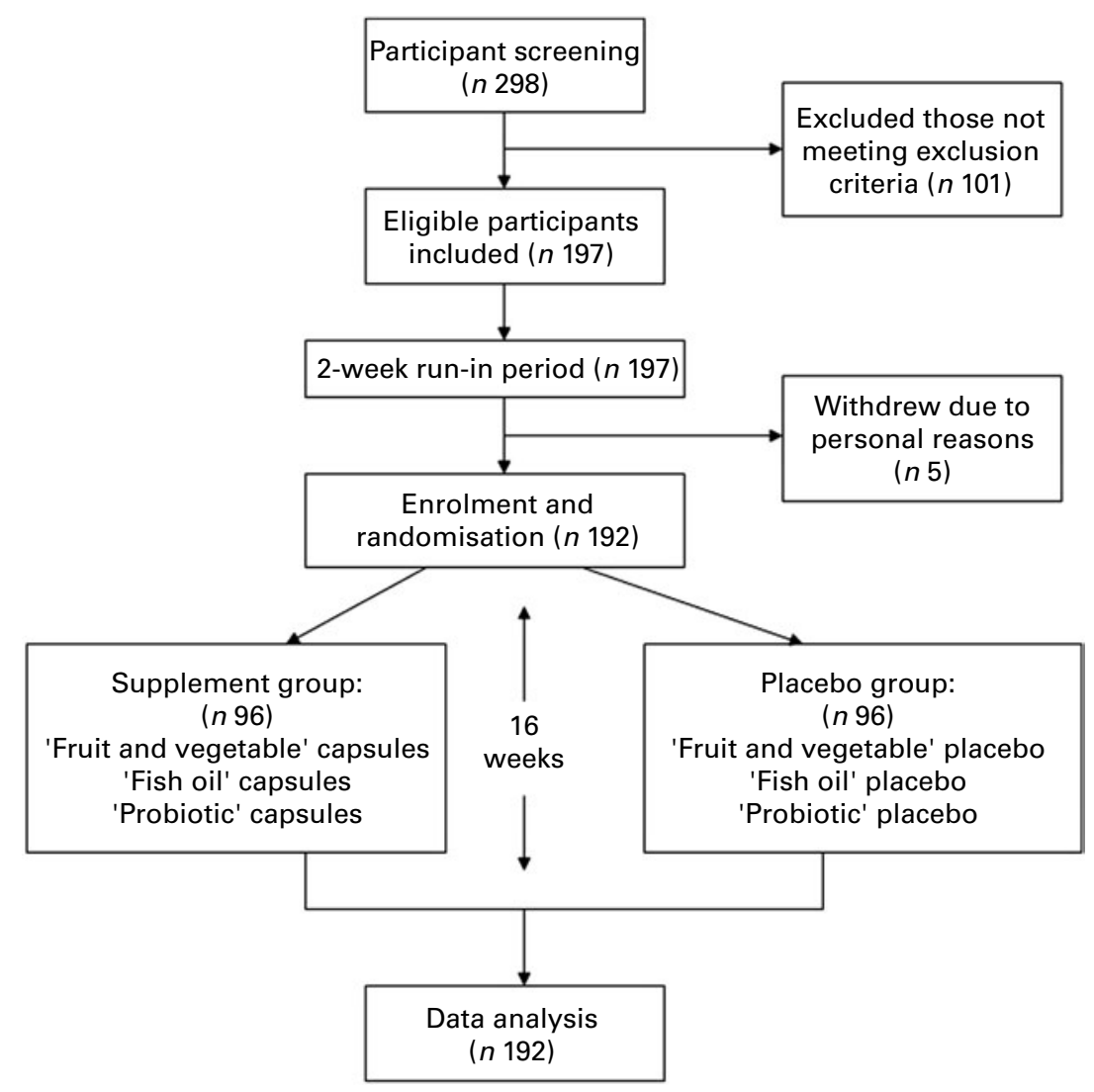

Fig. 1. Study design.

supplement group or the placebo group (Fig. 1). Stratified randomisation was carried out with stratification by sex, age and clinical site (children's school), as boys or younger children are known to have a higher risk of asthma. In addition, local environmental exposures such as weather, allergens and air pollution needed to be balanced between the experimental group and the control group.

The capsules were distributed to the children in schools by on-site workers. The supplements were given to the children personally in the morning, to ensure that the children took the capsules from Monday to Friday. In addition, the personnel reminded the children to take their capsules at home on weekends. The children were asked to take all unused capsules back to school. During the intervention period, children saw doctors and maintained their regular lifestyle and exercise habits as usual. Participants were monitored via an interview for serious adverse events and side effects such as prolonged epistaxis, bleeding tendency and gastrointestinal symptoms.

\section{Clinical assessment and outcomes}

Assessments were carried out at baseline, and at weeks 8 and 16 of the trial. Information on socio-demographic characteristics, risk factors for asthma, medications, usual dietary intake and the use of dietary supplements was collected at baseline. Dietary intake was measured using a twentyeight-item FFQ to compare the frequency distribution of fruits, vegetables, $n$-3-rich oily fish and probiotic-related food intake between the two groups.

Asthma-related quality of life was measured using the Paediatric Asthma Quality of Life Questionnaire (PAQLQ) that consists of twenty-three items ${ }^{(19)}$. The total score ranges from 1 to 7 ( 1 indicates maximum impairment and 7 indicates no impairment).

The Childhood Asthma Control Test ${ }^{(20)}$ (CACT) was used to evaluate how well the children's asthma was controlled. The reliability and validity of this test have been demonstrated previously in Chinese children ${ }^{(20)}$. The CACT was completed jointly by children and their parent(s) or caregiver(s). The CACT includes seven items and has a total score ranging from 0 to 27. The higher the score, the better the asthma control. Inadequately controlled asthma was defined as a CACT score less than $19^{(20)}$

Pulmonary function was measured using a portable spirometer (MiniSpir, Medical International Research, Inc.) according to the American Thoracic Society guidelines. The highest values of $\mathrm{FEV}_{1}$, forced vital capacity (FVC) and peak expiratory flow rate from the 'American Thoracic Society best test' were used in the analyses ${ }^{(21)}$. FEV1 is an important clinical index of pulmonary function. The ratio of $\mathrm{FEV}_{1}$ :FVC (or $\mathrm{FEV}_{1} \%$ ) should be approximately above $80 \%$ in healthy adults and above $90 \%$ in healthy children. When the airway is obstructed, $\mathrm{FEV}_{1}$ and $\mathrm{FEV}_{1} \%$ are lower than the normal limit ${ }^{(22)}$. Participants were asked to avoid taking bronchodilators within $4 \mathrm{~h}$ of the test ( $8 \mathrm{~h}$ for long-acting bronchodilators). 
Pulmonary function was measured at approximately the same time of day at baseline and follow-up.

During the intervention period, daily medication usage was recorded by the parent/caregiver. The recorded information was checked by the study coordinator and was clarified with parents whenever necessary. Collected data included name, frequency and dosage of the medications and date of consumption. Information on short-acting inhaled bronchodilators, inhaled corticosteroids (ICS), oral steroids and leukotriene receptor antagonists was included in the statistical analysis.

The erythrocyte membrane arachidonic acid, EPA and DHA compositions were analysed using GC. The procedure has been described in detail elsewhere ${ }^{(23)}$.

\section{Sample size estimation}

Differences in PAQLQ and $\mathrm{FEV}_{1}$ between the two groups were used to estimate the sample size. The standard deviation for the change in PAQLQ score was assumed to be $0.6^{(24)}$. We estimated that fifteen participants in each group would give $95 \%$ power at $5 \%$ significance level to detect a mean difference of 0.78 between the supplement and placebo group for the change in PAQLQ score between baseline and the end of the trial. We also used $\mathrm{FEV}_{1}$ to calculate the sample size. Assuming a standard deviation for the change in $\mathrm{FEV}_{1}$ of 0.41 litres $^{(25)}$, we estimated that 102 participants in each group would give $80 \%$ power at the $5 \%$ significance level to detect a mean difference of 0.16 litres between the supplement and the placebo group for the change in $\mathrm{FEV}_{1}$ between baseline and the end of the trial. Therefore, we aimed for a sample size of about 100 participants in each group.

\section{Statistical analysis}

Student's $t$ test for continuous variables and $\chi^{2}$ test for categorical variables were used to compare characteristics between the treatment and control groups. For the outcome analysis, the Student's $t$ test was used to compare the change from baseline to week 8 and week 16 between the two groups in PAQLQ score (Table 2), CACT score (Table 2), pulmonary function parameters (Table 3) and the mean frequency of medication use (Fig. 3). Mixed models were used to control for potential confounding factors including age, sex, BMI, cluster effect (children's school) and seasonal effect. McNemar's test was used to examine the change in proportion of children using medication during the 1st period (1st to 8th week) and the 2 nd period (1st to 16th week) of the trial. The proportional $Z$ test was used to compare the difference in the change in proportion using medication between the two groups (Fig. 2).

\section{Results}

A total of 192 participants completed the trial. The follow-up rate achieved $100 \%$ and no serious adverse events or side effects were reported (Fig. 1).

\section{Baseline characteristics and participant compliance}

At baseline, the distributions of age, sex, BMI, medication usage, pulmonary function, PAQLQ scores and CACT scores were similar in the supplement and placebo groups (Table 1). The frequency of FVFP formula-related foods (vegetables, fruit, oily fish, Yakult and yogurt) and other foods (milk, cheese, eggs, fish, shellfish, meat, soya bean milk, soya bean products, sweet drinks, desserts and candy) were non-significantly different between the two groups at baseline (Table S1, available online) as well as during the intervention (Table S2, available online). On average (Table S1, available online), these children consumed vegetables about three times per $\mathrm{d}$ and fruit once per $d$. In addition, they consumed candy, sweet drinks or desserts about ten times per week, milk five times per week, yogurt or Yakult three times per week and cheese 1.5 times per week, and fish four times per week. Around one-third of these fish were oily fish. Information on portion sizes was not requested. According to the $24 \mathrm{~h}$ dietary recall data from the Nutrition and Health Survey in Taiwan, elementary school children consume about $33 \mathrm{~g}$ of vegetables (raw and uncooked form), $150 \mathrm{~g}$ of fruits and $40 \mathrm{~g}$ of fish each time. Therefore, children in the present study ingested one serving of vegetables and 1.5 servings of fruit per $\mathrm{d}$, and 1.5 servings of oily fish per week, but relatively little Lactobacillus-containing foods.

Participant compliance was assessed by capsule counting and by the level of EPA and DHA in the erythrocyte membrane. The capsule consumption rate was $91 \%$ (no. of consumption days/total no. of intervention days) in both groups. The levels of EPA, DHA and arachidonic acid in the erythrocyte membrane were non-significantly different between the two groups at baseline. However, at the end of the trial, the levels of EPA and DHA in the supplement group were significantly higher than those in the placebo group (EPA: $1.66 v .0 .77 \%$, $P<0.001$; DHA: $6.77 v .5 .97 \%, P=0.001)$. In contrast, the arachidonic acid:EPA ratio (2.10 (SD 0.49) v. $2 \cdot 70$ (SD 10.61), $P<0 \cdot 001$ ) and $n-6: n-3$ fatty acid ratio (7.32 (SD 3.84) v. $16 \cdot 40$ (SD 7.56), $P<0.001$ ) were significantly lower in the supplement group than in the placebo group. These results demonstrate that participants had good compliance.

\section{Paediatric Asthma Quality of Life Questionnaire and Childhood Asthma Control Test evaluation}

The change in PAQLQ and CACT scores from baseline to week 8 and week 16 was non-significantly different between the two groups (Table 2).

\section{Assessment of change in medication usage}

The supplement group demonstrated a smaller increase in the percentage of children using short-acting inhaled bronchodilators than the placebo group during the 1st to the 8 th week $(P=0 \cdot 10)$ and during the 1 st to the 16th week $(P=0.006)$ (Fig. 2(a)). In addition, the proportion of children using ICS decreased in the supplement group, but increased in the placebo group. This difference in the change in use of ICS between the supplement and placebo groups was statistically 

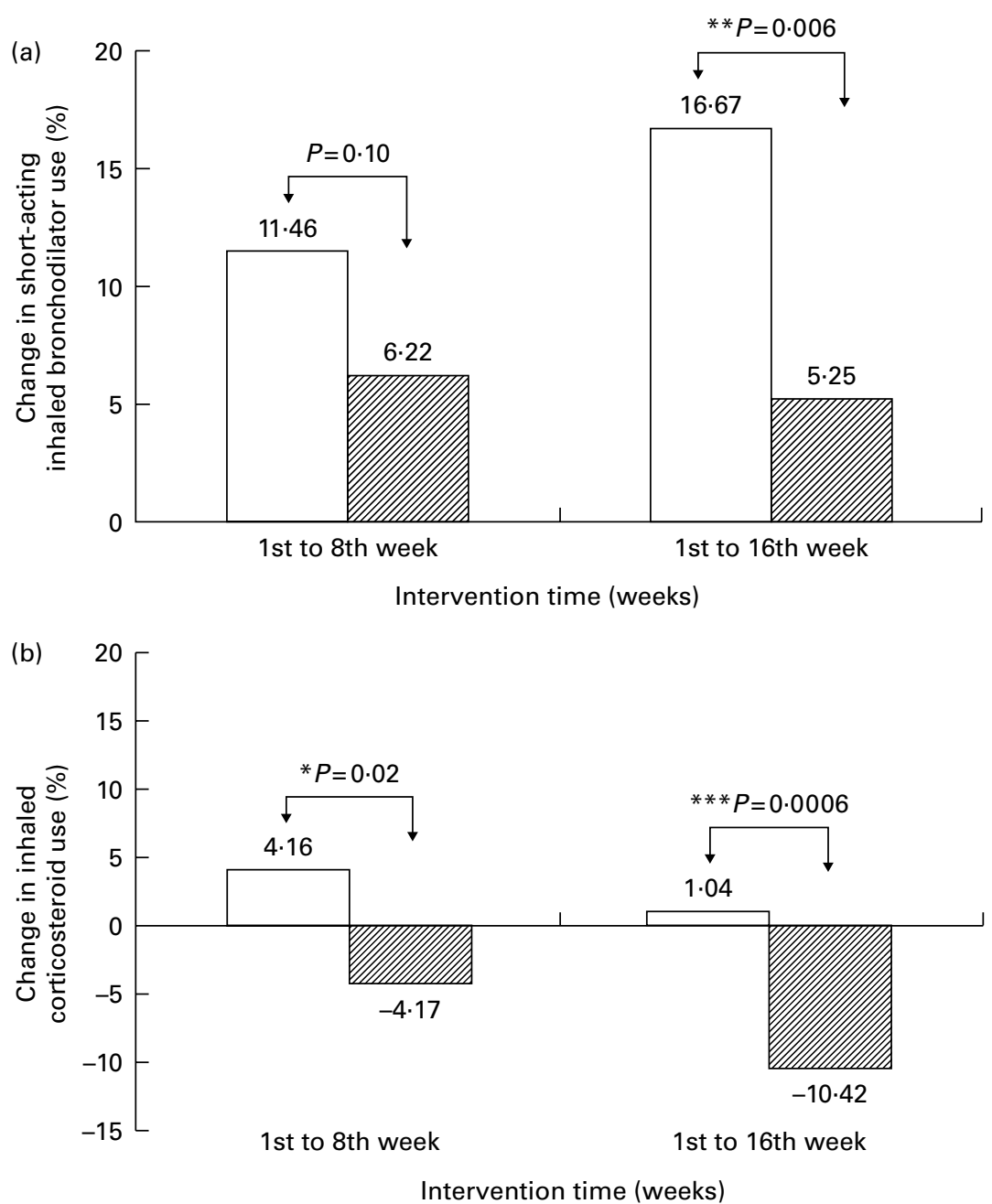

Fig. 2. Change in percentage of children using (a) short-acting inhaled bronchodilators and (b) inhaled corticosteroids from baseline by supplementation status. The percentage of children using (a) and (b) was 15.6 and $21.9 \%$ at baseline in the supplement ( $\square$ ) group, and 19.8 and $16.7 \%$ in the placebo ( $\square$ ) group. McNemar's test was used to examine the change in proportion of children using medication during the 1st period (1st to 8th week) and the 2nd period (1st to 16 th week) of the trial. The proportional $Z$ test was used to compare the difference in the change in proportion using medication between the two groups. ${ }^{*} P<0.05$, ${ }^{\star *} P<0.01,{ }^{* \star *} P<0.001$.

significant for the 1 st to the 8 th week $(P=0.02)$ and for the 1 st to the 16th week $(P=0 \cdot 0006)$ (Fig. 2(b)). Use of oral steroids and leukotriene receptor antagonists was relatively infrequent compared with the earlier two medicines, and the percentage change in their use was non-significantly different between the two groups (data not shown).

We also evaluated the frequency of medication use in children who were taking medication during the trial period (Fig. 3). Use of short-acting inhaled bronchodilators during the 1 st to the 8 th week $(P=0 \cdot 24)$ declined by $0 \cdot 21$ times per week in the supplement group, while it increased by 0.34 times per week in the placebo group. Use of this medication during the 1 st to the 16 th week $(P=0 \cdot 19)$ declined by 0.04 times per week in the supplement group, while it increased by 0.41 times per week in the placebo group (Fig. 3(a)). In addition, the supplement group demonstrated a downward trend in the frequency of use of ICS, whereas the placebo group demonstrated an upward trend. The change in frequency of the use of ICS from the 1st to the 8th week
$(P=0 \cdot 06)$ and from the 1 st to the 16 th week $(P=0 \cdot 009)$ was significantly different between the two groups (Fig. 3(b)). This difference remained in the mixed model after controlling for age, sex, BMI, cluster effect (children's school) and seasonal effect.

\section{Pulmonary function evaluation}

In the analysis of pulmonary function, the supplement group showed a significantly higher increment in $\mathrm{FEV}_{1}$ $(P=0 \cdot 01)$, FVC $(P=0 \cdot 01)$ and $\mathrm{FEV}_{1}: \mathrm{FVC}$ ratio $(P=0 \cdot 008)$ in the 16th week compared with the placebo group. These significant associations remained, even after controlling for confounders (Table 3).

\section{Discussion}

This double-blind, 16-week, randomised intervention trial showed that FVFP supplementation had a significantly 
Table 1. Baseline socio-demographic and clinical characteristics in the supplement and placebo groups

(Mean values and standard deviations; number of subjects and percentages)

\begin{tabular}{|c|c|c|c|c|c|}
\hline & \multicolumn{2}{|c|}{$\begin{array}{l}\text { Supplement } \\
\text { group }(n 96)\end{array}$} & \multicolumn{2}{|c|}{$\begin{array}{l}\text { Placebo group } \\
\quad(n 96)\end{array}$} & \multirow[b]{2}{*}{$P^{*}$} \\
\hline & Mean & SD & Mean & SD & \\
\hline Age (years) & $11 \cdot 0$ & 0.8 & 11.0 & 0.8 & 1.00 \\
\hline Male & & & & & 0.53 \\
\hline$n$ & \multicolumn{2}{|c|}{$68 \cdot 0$} & \multicolumn{2}{|c|}{$64 \cdot 0$} & \\
\hline$\%$ & \multicolumn{2}{|c|}{$70 \cdot 8$} & \multicolumn{2}{|c|}{$66 \cdot 7$} & \\
\hline $\mathrm{BMI}\left(\mathrm{kg} / \mathrm{m}^{2}\right)$ & $19 \cdot 6$ & 3.6 & $19 \cdot 8$ & 4.4 & 0.70 \\
\hline \multicolumn{6}{|l|}{ Medications } \\
\hline Short-acting inhaled bronchodilators & & & & & 0.34 \\
\hline$n$ & \multicolumn{2}{|c|}{14.0} & \multicolumn{2}{|c|}{$19 \cdot 0$} & \\
\hline$\%$ & \multicolumn{2}{|c|}{$15 \cdot 6$} & \multicolumn{2}{|c|}{$19 \cdot 8$} & \\
\hline Inhaled corticosteroids & \multirow{2}{*}{\multicolumn{2}{|c|}{21.0}} & & & 0.36 \\
\hline$n$ & & & \multicolumn{2}{|c|}{$16 \cdot 0$} & \\
\hline$\%$ & \multicolumn{2}{|c|}{21.9} & \multicolumn{2}{|c|}{$16 \cdot 7$} & \\
\hline Oral steroids & \multirow{2}{*}{\multicolumn{2}{|c|}{2.0}} & & & 0.56 \\
\hline$n$ & & & \multicolumn{2}{|c|}{$1 \cdot 0$} & \\
\hline$\%$ & \multicolumn{2}{|c|}{$2 \cdot 1$} & \multicolumn{2}{|c|}{1.0} & \\
\hline Leukotriene receptor antagonists & & & & 0.77 \\
\hline$n$ & & & \multicolumn{2}{|c|}{$6 \cdot 0$} & \\
\hline$\%$ & \multicolumn{2}{|c|}{$7 \cdot 3$} & \multicolumn{2}{|c|}{$6 \cdot 3$} & \\
\hline \multicolumn{6}{|l|}{ Pulmonary function } \\
\hline $\mathrm{FEV}_{1}$ (litres) & 2.01 & 0.41 & 2.01 & 0.42 & 0.97 \\
\hline FVC (litres) & $2 \cdot 37$ & 0.53 & 2.39 & 0.50 & 0.84 \\
\hline PEFR (litres/s) & 4.78 & 0.93 & 4.74 & 0.82 & 0.80 \\
\hline PAQLQ score & 5.92 & 0.96 & 5.93 & 0.97 & 0.97 \\
\hline CACT score & 21.73 & 2.98 & $21 \cdot 34$ & $3 \cdot 20$ & 0.39 \\
\hline
\end{tabular}

$\mathrm{FEV}_{1}$, forced expiratory volume in $1 \mathrm{~s} ; \mathrm{FVC}$, forced vital capacity; PEFR, peak expiratory flow rate; PAQLQ, Paediatric Asthma Quality of Life Questionnaire; CACT, Childhood Asthma Control Test.

* $P$ value was estimated using the Student's $t$ test for continuous variables and $\chi^{2}$ test for categorical variables.

beneficial effect on asthma symptom control in children residing in metropolitan Taipei. Although there was no significant improvement in PAQLQ and CACT scores, the FVFP supplement reduced the usage percentage and frequency of short-acting inhaled bronchodilators and ICS, and improved several measures of pulmonary function $\left(\mathrm{FEV}_{1}, \mathrm{FVC}\right.$ and $\mathrm{FEV}_{1}: \mathrm{FVC}$ ).

To date, there have been few trials investigating the supplemental effect of multiple beneficial food components on asthma control. Findings have been controversial, as to the effects of single supplements such as antioxidative vitamins, minerals, vegetables or fruits, fish oil and probiotics alone $^{(9-13,15,26-37)}$. A randomised, double-blind clinical trial of supplementation with vitamin $\mathrm{C}^{(26)}$ ( $1 \mathrm{~g}, 16$ weeks), vitamin $\mathrm{E}^{(27)} \quad(500 \mathrm{mg}, \quad 6$ weeks $)$, vitamins $\mathrm{C}+\mathrm{E}^{(28)}$ $\left(1 \mathrm{~g}+500 \mathrm{mg}, 12\right.$ weeks), $\mathrm{Mg}^{(26,29)}$ ( $450 \mathrm{mg}$ for 16 weeks or $340 \mathrm{mg}$ for 6.5 months) and $\mathrm{Se}^{(30)}(100 \mathrm{mg}, 24$ weeks $)$ in adults aged 16-60 years showed no beneficial effects on pulmonary function, asthma symptoms or medication use, despite high levels of antioxidative vitamins or minerals being observed in the blood. Only one trial with $\mathrm{Mg}^{(31)}$ supplementation (300 mg, 2 months) in children aged $7-19$ years ( $n$ 37)

Table 2. Mean change in the Paediatric Asthma Quality of Life Questionnaire (PAQLQ) and the Childhood Asthma Control Test (CACT) scores from baseline in the supplement and placebo groups

(Mean values and $95 \%$ confidence intervals)

\begin{tabular}{|c|c|c|c|c|c|c|}
\hline \multirow[b]{2}{*}{ Mean score change } & \multirow[b]{2}{*}{ Supplement group ( $n$ 96) } & \multirow[b]{2}{*}{ Placebo group ( $n$ 96) } & \multicolumn{2}{|c|}{ Difference } & \multirow[b]{2}{*}{$P^{*}$} & \multirow[b]{2}{*}{$P$-adjusted } \\
\hline & & & Mean & $95 \% \mathrm{Cl}$ & & \\
\hline \multicolumn{7}{|l|}{ PAQLQ score‡ } \\
\hline 8th week & 0.16 & 0.22 & -0.06 & $-0.16,0.28$ & 0.58 & 0.58 \\
\hline 16th week & 0.34 & 0.44 & -0.10 & $-0.13,0.32$ & 0.40 & 0.42 \\
\hline \multicolumn{7}{|l|}{ CACT score $\ddagger$} \\
\hline 8th week & 1.07 & 1.56 & -0.49 & $-0.46,1.44$ & 0.31 & 0.31 \\
\hline 16 th week & 2.05 & $2 \cdot 27$ & -0.22 & $-0.72,1 \cdot 16$ & 0.65 & 0.68 \\
\hline
\end{tabular}

* Mean values were significantly different between the two groups (Student's $t$ test).

†A mixed model was used to adjust for age, sex, BMI, cluster effect (children's school) and seasonal effect (intervention phase) when comparing the two groups.

¥ The mean PAQLQ score was 5.92 (SD 0.96) at baseline in the supplement group and 5.93 (SD 0.97) in the placebo group; the mean CACT score was 21.73 (SD 2.98) at baseline in the supplement group and 21.34 (SD 3.20) in the placebo group. 

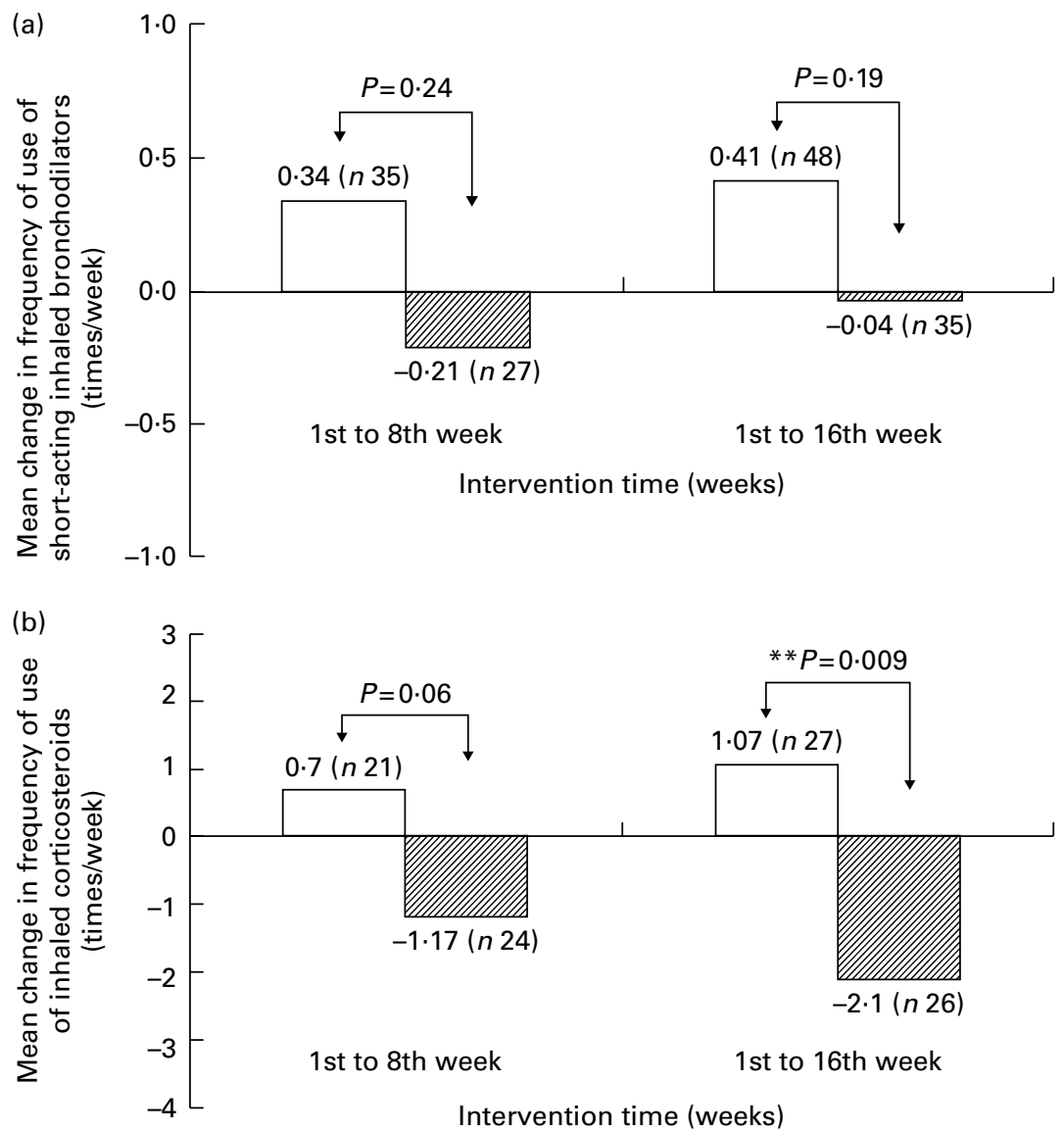

Fig. 3. Change in mean frequency of medication use in children using medication by supplementation status. (a) Short-acting inhaled bronchodilators and (b) inhaled corticosteroids. The mean frequency of use of (a) and (b) was 0.82 (SD 1.51) and 5.70 (SD 6.80) times/week at baseline in the supplement ( $\square$ ) group, and

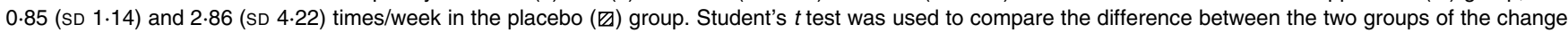
from baseline to week 8 and week $16 .{ }^{* *} P<0.01$.

found that $\mathrm{Mg}$ reduced bronchial reactivity to methacholine ( $\mathrm{PC}_{20}$ (provocative concentration of methacholine causing a $20 \%$ fall in $\left.\left.\mathrm{FEV}_{1}\right), P<0.05\right)$, the number of days of asthma exacerbation episodes $(P=0.002)$ and use of inhaled salbutamol $(P<0 \cdot 0001)$. However, there was no significant change in $\mathrm{FEV}_{1}$, $\mathrm{FVC}$ or $\mathrm{FEV}_{1}: \mathrm{FVC}$ ratio. In another study, asthmatic adults supplemented with tomato products for $7 \mathrm{~d}^{(32)}$, or asthmatic children supplemented with fruits (apples, oranges, pears and pear) for 1 year ${ }^{(33)}$ demonstrated no improvement. Supplementation with purple passion fruit peel powder for 4 weeks has been reported to reduce the prevalence of wheeze $(P<0 \cdot 001)$, cough $(P<0.001)$ and shortness of breath $(P<0.05)$ in asthmatic adults aged $18-60$ years ${ }^{(34)}$. Short-term trials in asthmatic adults failed to demonstrate improvement in pulmonary function, asthma symptoms or medication use with low-dose fish oil $^{(10,11)}$ (EPA + DHA $780 \mathrm{mg}$ for 2 weeks or $690 \mathrm{mg}$ for 5 weeks), whereas long-term (1 year) supplementation with low-dose fish oil ${ }^{(35)}$ ( $\left.1 \mathrm{~g}\right)$ demonstrated significant improvement in $\mathrm{FEV}_{1}$ up to 9 months after the intervention. Highdose, short-term fish oil $^{(9,13)}$ supplementation (EPA + DHA $5.4 \mathrm{~g}$ for 3 weeks or $2.58 \mathrm{~g}$ for 4 weeks) can decrease bronchial hyperreactivity $(P<0.05)$ in adults with exercise-induced bronchoconstriction or seasonal asthma. Using a dose of fish oil similar to that in the present study, a long-term (10 months) randomised controlled trial in twenty-nine Japanese asthmatic children found that fish oil supplementation reduces bronchial reactivity to methacholine ( $\mathrm{PC} 20, P<0.05)$ and asthma score $(P<0.05)$ at 24 weeks $^{(12)}$. In trials of probiotic supplements, a short-term (2 months) trial using L. gasseri A5 supplements in asthmatic children aged 6-12 years found that probiotics can improve peak expiratory flow rate levels and CACT score $(P<0.05)$, and can significantly decrease levels of TNF- $\alpha$, interferon- $\gamma$, IL-12 and IL-13 production by peripheral blood mononuclear cells ${ }^{(15)}$. However, supplementation with L. casei $i^{(36)}$ for 12 months or non-pathogenic Enterococcus faecalis $^{(37)}$ for 17 weeks had no beneficial effect on asthma control in asthmatic children.

Two trials have investigated the beneficial effects of multiple nutrient supplements, which combine fish oil and antioxidative vitamins and minerals, on asthma control. A randomly assigned, 6-week, cross-over intervention, placebo, self-controlled trial in sixty children (aged 4-11 years) with moderately persistent asthma investigated the effects of supplementation with each of fish oil (EPA + DHA $300 \mathrm{mg}$ ), vitamin C (200 mg) and $\mathrm{Zn}(15 \mathrm{mg})$ and a combination of the three. The study found that supplementation with a 
Table 3. Mean change in pulmonary function parameter estimates from baseline in the supplement and placebo groups (Mean values and $95 \%$ confidence intervals)

\begin{tabular}{|c|c|c|c|c|c|c|}
\hline \multirow{2}{*}{$\begin{array}{l}\text { Pulmonary function } \\
\text { parameter }\end{array}$} & \multirow[b]{2}{*}{ Supplement group ( $n$ 96) } & \multirow[b]{2}{*}{ Placebo group ( $n$ 96) } & \multicolumn{2}{|c|}{ Difference } & \multirow[b]{2}{*}{$P^{*}$} & \multirow[b]{2}{*}{$P$ adjusted $\dagger$} \\
\hline & & & Mean & $95 \% \mathrm{Cl}$ & & \\
\hline \multicolumn{7}{|l|}{ FVC (ml)‡ } \\
\hline 8th Week & 61 & 19 & 42 & $-29,113$ & 0.24 & 0.21 \\
\hline 16th Week & 178 & 91 & 87 & 20,155 & 0.01 & 0.007 \\
\hline \multicolumn{7}{|l|}{$\mathrm{FEV}_{1}(\mathrm{ml}) \ddagger$} \\
\hline 8th Week & 28 & 33 & -5 & $-87,76$ & 0.90 & 0.93 \\
\hline 16th Week & 107 & 40 & 67 & 15,120 & 0.01 & 0.007 \\
\hline \multicolumn{7}{|l|}{ PEFR $(\mathrm{ml} / \mathrm{s}) \ddagger$} \\
\hline 8th Week & 115 & 91 & 24 & $-141,189$ & 0.77 & 0.66 \\
\hline 16th Week & 241 & 158 & 83 & $-60,226$ & 0.25 & 0.19 \\
\hline \multicolumn{7}{|l|}{$\mathrm{FEV}_{1}: \mathrm{FVC}$ ratio $(\%) \ddagger$} \\
\hline 8th Week & 1.7 & 1.7 & 0 & $-4 \cdot 2,4 \cdot 2$ & 0.99 & 0.96 \\
\hline 16th Week & 4.8 & 1.6 & 3.2 & $9 \cdot 0,5 \cdot 6$ & 0.008 & 0.004 \\
\hline
\end{tabular}

FVC, forced vital capacity; FEV $_{1}$, forced expiratory volume in $1 \mathrm{~s} ;$ PEFR, peak expiratory flow rate.

${ }^{*}$ Mean values were significantly different between the two groups (Student's $t$ test).

†A mixed model was used to adjust for age, sex, BMI, cluster effect (children's school) and seasonal effect when comparing the two groups.

$\ddagger$ At baseline, the FVC was 2.39 (SD 0.50) litres in the supplement group and 2.37 (SD 0.53) litres in the placebo group; the FEV 1 was 2.01 (SD 0.42 ) litres in the supplement group and 2.01 (SD 0.41) litres in the placebo group; the PEFR was 4.78 (SD 0.93) litres/s in the supplement group and 4.74 (SD 0.82 ) litres/s in the placebo group; the $\mathrm{FEV}_{1}$ :FVC ratio was 85.4 (SD 6.9 ) \% in the supplement group and 84.8 (SD 7.7 ) \% in the placebo group.

single nutrient significantly improved the CATC score, $\mathrm{FEV}_{1}$ and sputum inflammatory markers $(P<0 \cdot 001)$. Significant improvements were also observed in those taking combined supplements compared with any single supplement $(P<0 \cdot 001)^{(38)}$. The second randomised, double-blind, placebo-controlled, parallel group trial in forty-three children (aged 6-14 years) with mildly to moderately persistent asthma investigated the supplementation of a novel nutritional formula (rich in EPA + DHA $300 \mathrm{mg}$, antioxidative vitamins and minerals) and found that it reduced bronchial reactivity to methacholine $\left(\mathrm{PC}_{20}, P<0.05\right)$ and decreased inflammatory markers (serum IgE, eNO and eosinophil cationic protein). However, asthma symptoms and bronchodilator usage were non-significantly different compared with the placebo group. In addition, although the $\mathrm{FEV}_{1}$ and $\mathrm{FEV}_{1}: \mathrm{FVC}$ ratio increased to $130 \mathrm{ml}$ (placebo group: $20 \mathrm{ml}$ ) and $3.8 \%$ (0\%) from baseline to the 12th week, the difference between the treatment and control groups was not statistically significant ${ }^{(39)}$.

The present study is the first to combine multiple beneficial food components in the forms of food extract concentrates rather than pure synthetic compounds. The present findings are superior to other studies investigating a single $(9-11,13,26-30,32,33,35-37)$ or multiple nutrient supplements ${ }^{(28,39)}$, as not only did we demonstrate a reduction in the percentage and frequency of use of short-acting inhaled bronchodilators and ICS, but we also demonstrated that use of our FVFP supplement significantly increased pulmonary function. The PAQLQ and CACT scores showed no significant difference between the two groups in the present study. This could be because children in both groups were prescribed with medication whenever needed, as the national health insurance scheme in Taiwan covers routine paediatri-

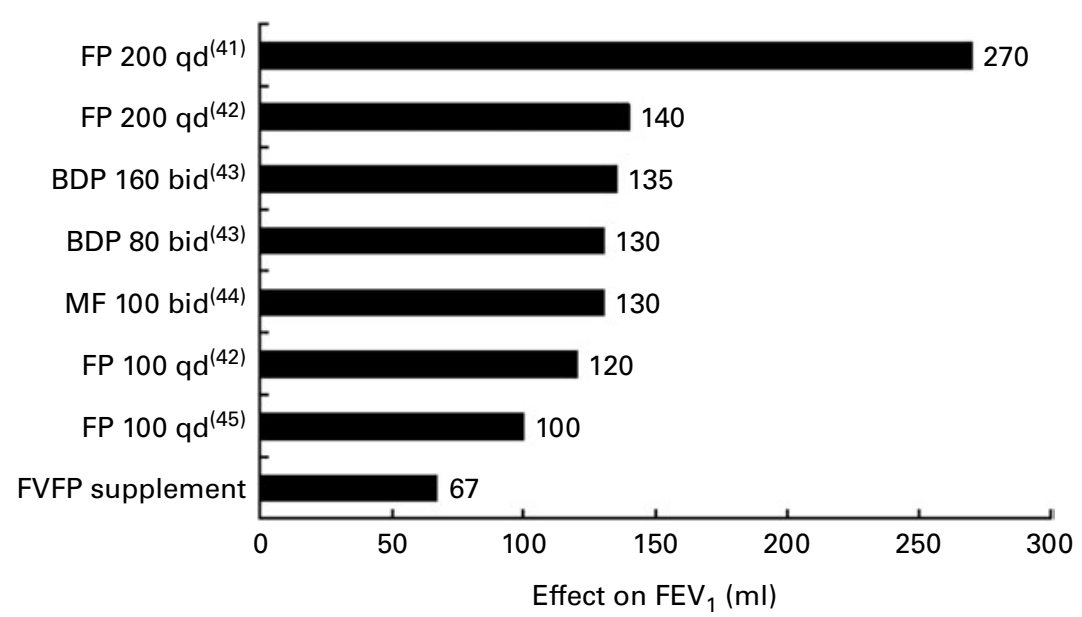

Fig. 4. Forced expiratory volume in $1 \mathrm{~s}\left(\mathrm{FEV}_{1}\right)$ improvement (the improvement effect was the effect of intervention group minus that of the placebo group. More detailed information of the improved $\mathrm{FEV}_{1}$ and $\mathrm{FEV}_{1} \%$ with asthma medication are provided in Table S3 (available online)) after 'fruit and vegetable' capsules, 'fish oil' capsules and 'probiotic' capsules (FVFP supplementation) compared with asthma medications in mildly to moderately asthmatic children. FP, fluticasone propionate; qd, once per d; BDP, beclomethasone dipropionate; bid, twice per d; MF, mometasone furoate. 
cian visits, resulting in diminished difference in scores between the two groups.

The global guideline for asthma management of the Global Initiative for Asthma recommends that rapid-acting inhaled $\beta 2$-agonist (when required) and low-dose ICS are used for asthma control as the first step; and high-dose ICS or highdose ICS plus long-acting inhaled $\beta 2$-agonist combinations are used to augment asthma control for patients with poor control $^{(40)}$. The FVFP supplement for 16 weeks was able to improve $\mathrm{FEV}_{1}$ by $67 \mathrm{ml}$ and $\mathrm{FEV}_{1}: \mathrm{FVC}$ ratio by $3.2 \%$ in asthmatic children. The improvement effect was almost a half in magnitude compared with various low-dose $\operatorname{ICS}^{(41-46)}$ (Fig. 4). Although more clinical trials are needed to confirm the present finding and to compare the effects of FVFP supplementation or a diet rich in FVFP with various asthmatic medications, a FVFP supplement or diet may be used as an adjuvant non-pharmacological therapy to the regular asthma medication. It may reduce the dosage of ICS and diminish side effects.

The nutrients contained in these dietary supplements can be equated to natural food intake in the diet. The two capsules of 'fruit and vegeables' are equivalent to a total of four servings of fruits and vegetables. The three to five capsules of 'fish oil' (EPA + DHA: 1065-1775 mg) are equivalent to one serving of Pacific saury ( $35 \mathrm{~g}, \mathrm{EPA}+\mathrm{DHA}=1598 \mathrm{mg}$ ), $0 \cdot 5-1$ serving of tuna $(30 \mathrm{~g}, \mathrm{EPA}+\mathrm{DHA}=2132 \mathrm{mg})$ or $1 \cdot 5-2.5$ servings of salmon sashimi $(30 \mathrm{~g}, \mathrm{EPA}+\mathrm{DHA}=673$ $\mathrm{mg}$ ). The amount of probiotic provided is equivalent to one to two servings of yogurt. Other fermented foods are also rich in probiotics such as cheese, pickles or sauerkraut. The FVFP supplements that we provided are more comparable with what the children consumed on average, i.e. about one serving of vegetables and 1.5 servings of fruits per $d, 1.5$ servings of oily fish per week and three cups of either yogurt or Yakult per week. However, adding together the original dietary intake and supplements, the total amount of vegetables and fruits ( 6.5 servings), yogurt ( 1.5 servings $)$ and oily fish (one serving) required are achievable through dietary means. A portion of common antioxidant-poor, but energyrich foods served in the everyday life of a Taiwanese may be replaced, e.g. deep-fried pork chop or chicken breast (replaced by oily fish), pickled vegetables (by fresh vegetables), diluted and sweetened soya milk (by yogurt) and polished white rice (by brown rice).

The present study has several limitations. We did not use a factorial design to study the effects of the single items and the combined supplement, as it would have required a large sample size. Further studies may be needed to investigate the magnitude of the effects in individual items and whether there are interactions among the multiple food components. Moreover, future studies could investigate the beneficial effects of the FVFP supplement over a wider age range and in asthmatic patients with moderate-to-severe persistent asthma.

\section{Conclusion}

Combining vegetable and fruit concentrate, fish oil and probiotics significantly reduces the usage percentage and fre- quency of short-acting inhaled bronchodilators and ICS, and improved pulmonary function in asthmatic children. The reduction in medication use could help to avoid medication side effects and to reduce medical expenditure. The present study suggests that a dietary pattern featuring adequate amounts of vegetables and fruit, fish and probiotic foods should be recommended in asthma prevention guidelines.

\section{Supplementary material}

To view supplementary material for this article, please visit http://dx.doi.org/10.1017/S0007114512004692

\section{Acknowledgements}

We are indebted to the children and their families for participating in the present scientific investigation. We also thank Schiff Nutrition Group, Inc. for supplying the fruit plus vegetable concentrate and ProMD Biotech Company, Limited for supplying the probiotic capsules. The authors' responsibilities were as follows: S.-C. L. designed the research, conducted the research, analysed and interpreted the data and wrote the manuscript; W.-H. P. designed the research, interpreted the data and had responsibility for the final content; Y.-H. Y. collected and interpreted the data; S.-Y. C. provided statistical consultation and interpreted the data. S.-Y. H. analysed the fatty acid composition of erythrocyte membranes. All of the authors read and approved the final manuscript. None of the authors has any conflicts of interest to report. The present study was supported by a grant (NSC96-2628-B-001-025-MY2) from the National Science Council, Taiwan and by intramural funds from Institute of Biomedical Science, Academia Sinica and from the Institute of Population Health Sciences, National Health Research Institutes, Taiwan.

\section{References}

1. Allan K \& Devereux G (2011) Diet and asthma: nutrition implications from prevention to treatment. J Am Diet Assoc 111, 258-268.

2. Lee SC, Yang YH, Chuang SY, et al. (2012) Risk of asthma associated with energy-dense but nutrient-poor dietary pattern in Taiwanese children. Asia Pac J Clin Nutr 21, $73-81$.

3. Cassano PA (2009) Nutritional effects on asthma aetiology and progression. Thorax 64, 560 .

4. Appel LJ, Moore TJ, Obarzanek E, et al. (1997) A clinical trial of the effects of dietary patterns on blood pressure. DASH Collaborative Research Group. N Engl J Med 336, 1117-1124.

5. Samman S, Sivarajah G, Man JC, et al. (2003) A mixed fruit and vegetable concentrate increases plasma antioxidant vitamins and folate and lowers plasma homocysteine in men. J Nutr 133, 2188-2193.

6. Plotnick GD, Corretti MC, Vogel RA, et al. (2003) Effect of supplemental phytonutrients on impairment of the flow-mediated brachial artery vasoactivity after a single high-fat meal. J Am Coll Cardiol 41, 1744-1749.

7. Nadeem A, Masood A \& Siddiqui N (2008) Oxidant-antioxidant imbalance in asthma: scientific evidence, epidemiologi- 
cal data and possible therapeutic options. Ther Adv Respir Dis 2, 215-235.

8. Chilton FH, Rudel LL, Parks JS, et al. (2008) Mechanisms by which botanical lipids affect inflammatory disorders. $A m J$ Clin Nutr 87, 498S-503S.

9. Mickleborough TD, Lindley MR, Ionescu AA, et al. (2006) Protective effect of fish oil supplementation on exerciseinduced bronchoconstriction in asthma. Chest 129, 39-49.

10. Schubert R, Kitz R, Beermann C, et al. (2009) Effect of $n-3$ polyunsaturated fatty acids in asthma after low-dose allergen challenge. Int Arch Allergy Immunol 148, 321-329.

11. Moreira A, Moreira P, Delgado L, et al. (2007) Pilot study of the effects of $n-3$ polyunsaturated fatty acids on exhaled nitric oxide in patients with stable asthma. J Investig Allergol Clin Immunol 17, 309-313.

12. Nagakura T, Matsuda S, Shichijyo K, et al. (2000) Dietary supplementation with fish oil rich in omega-3 polyunsaturated fatty acids in children with bronchial asthma. Eur Respir J 16, 861-865.

13. Villani F, Comazzi R, De Maria P, et al. (1998) Effect of dietary supplementation with polyunsaturated fatty acids on bronchial hyperreactivity in subjects with seasonal asthma. Respiration 65, 265-269.

14. Forsythe P (2011) Probiotics and lung diseases. Chest 139, 901-908.

15. Chen YS, Jan RL, Lin YL, et al. (2010) Randomized placebocontrolled trial of lactobacillus on asthmatic children with allergic rhinitis. Pediatr Pulmonol 45, 1111-1120.

16. van de Pol MA, Lutter R, Smids BS, et al. (2011) Synbiotics reduce allergen-induced T-helper 2 response and improve peak expiratory flow in allergic asthmatics. Allergy 66, 39-47.

17. Li CY, Lin HC, Hsueh KC, et al. (2010) Oral administration of Lactobacillus salivarius inhibits the allergic airway response in mice. Can J Microbiol 56, 373-379.

18. Beer C, Myers RA, Sorenson JH, et al. (2004) Comprehensive comparison of the antioxidant activity of fruit and vegetables based on typical serving sizes from common methods. Curr Top Nutraceutical Res 2, 227-250.

19. Juniper EF, Guyatt GH, Feeny DH, et al. (1996) Measuring quality of life in children with asthma. Qual Life Res 5, 35-46.

20. Chen HH, Wang JY, Jan RL, et al. (2008) Reliability and validity of Childhood Asthma Control Test in a population of Chinese asthmatic children. Qual Life Res 17, 585-593.

21. American Thoracic Society (1995) Standardization of Spirometry, 1994 Update. Am J Respir Crit Care Med 152, 1107-1136.

22. Bateman ED, Hurd SS, Barnes PJ, et al. (2008) Global strategy for asthma management and prevention: GINA executive summary. Eur Respir J 31, 143-178.

23. Chiu CC, Huang SY, Su KP, et al. (2003) Polyunsaturated fatty acid deficit in patients with bipolar mania. Eur Neuropsychopharmacol 13, 99-103.

24. Basaran S, Guler-Uysal F, Ergen N, et al. (2006) Effects of physical exercise on quality of life, exercise capacity and pulmonary function in children with asthma. J Rehabil Med 38, 130-135.

25. Bousquet J, D'Urzo A, Hebert J, et al. (2000) Comparison of the efficacy and safety of mometasone furoate dry powder inhaler to budesonide Turbuhaler. Eur Respir J 16, 808-816.

26. Fogarty A, Lewis SA, Scrivener SL, et al. (2003) Oral magnesium and vitamin $\mathrm{C}$ supplements in asthma: a parallel group randomized placebo-controlled trial. Clin Exp Allergy 33, $1355-1359$.

27. Pearson PJ, Lewis SA, Britton J, et al. (2004) Vitamin E supplements in asthma: a parallel group randomised placebo controlled trial. Thorax 59, 652-656.

28. Hernandez M, Zhou H, Zhou B, et al. (2009) Combination treatment with high-dose vitamin $\mathrm{C}$ and alpha-tocopherol does not enhance respiratory-tract lining fluid vitamin C levels in asthmatics. Inhal Toxicol 21, 173-181.

29. Kazaks AG, Uriu-Adams JY, Albertson TE, et al. (2010) Effect of oral magnesium supplementation on measures of airway resistance and subjective assessment of asthma control and quality of life in men and women with mild to moderate asthma: a randomized placebo controlled trial. J Asthma 47, 83-92.

30. Shaheen SO, Newson RB, Rayman MP, et al. (2007) Randomised, double blind, placebo-controlled trial of selenium supplementation in adult asthma. Thorax 62, 483-490.

31. Gontijo-Amaral C, Ribeiro MA, Gontijo LS, et al. (2007) Oral magnesium supplementation in asthmatic children: a double-blind randomized placebo-controlled trial. Eur $J$ Clin Nutr 61, 54-60.

32. Wood LG, Garg ML, Powell H, et al. (2008) Lycopene-rich treatments modify noneosinophilic airway inflammation in asthma: proof of concept. Free Radic Res 42, 94-102.

33. Fogarty AW, Antoniak M, Venn AJ, et al. (2009) A natural experiment on the impact of fruit supplementation on asthma symptoms in children. Eur Respir J 33, 481-485.

34. Watson RR, Zibadi S, Rafatpanah H, et al. (2008) Oral administration of the purple passion fruit peel extract reduces wheeze and cough and improves shortness of breath in adults with asthma. Nutr Res 28, 166-171.

35. Dry J \& Vincent D (1991) Effect of a fish oil diet on asthma: results of a 1-year double-blind study. Int Arch Allergy Appl Immunol 95, 156-157.

36. Giovannini M, Agostoni C, Riva E, et al. (2007) A randomized prospective double blind controlled trial on effects of longterm consumption of fermented milk containing Lactobacillus case i in pre-school children with allergic asthma and/or rhinitis. Pediatr Res 62, 215-220.

37. Stockert K, Schneider B, Porenta G, et al. (2007) Laser acupuncture and probiotics in school age children with asthma: a randomized, placebo-controlled pilot study of therapy guided by principles of Traditional Chinese Medicine. Pediatr Allergy Immunol 18, 160-166.

38. Biltagi MA, Baset AA, Bassiouny M, et al. (2009) Omega-3 fatty acids, vitamin $\mathrm{C}$ and $\mathrm{Zn}$ supplementation in asthmatic children: a randomized self-controlled study. Acta Paediatr 98, $737-742$.

39. Covar R, Gleason M, Macomber B, et al. (2010) Impact of a novel nutritional formula on asthma control and biomarkers of allergic airway inflammation in children. Clin Exp Allergy 40, 1163-1174.

40. O'Byrne PM (2010) Global guidelines for asthma management: summary of the current status and future challenges. Pol Arch Med Wewn 120, 511-517.

41. LaForce CF, Pearlman DS, Ruff ME, et al. (2000) Efficacy and safety of dry powder fluticasone propionate in children with persistent asthma. Ann Allergy Asthma Immunol 85, 407-415.

42. Peden DB, Berger WE, Noonan MJ, et al. (1998) Inhaled fluticasone propionate delivered by means of two different multidose powder inhalers is effective and safe in a large pediatric population with persistent asthma. J Allergy Clin Immunol 102, 32-38. 
43. Nayak A, Lanier R, Weinstein S, et al. (2002) Efficacy and safety of beclomethasone dipropionate extrafine aerosol in childhood asthma: a 12-week, randomized, double-blind, placebo-controlled study. Chest 122, 1956-1965.

44. Berger WE, Milgrom H, Chervinsky P, et al. (2006) Effects of treatment with mometasone furoate dry powder inhaler in children with persistent asthma. Ann Allergy Asthma Immunol 97, 672-680.
45. Katz Y, Lebas FX, Medley HV, et al. (1998) Fluticasone propionate 50 micrograms BID versus 100 micrograms BID in the treatment of children with persistent asthma. Fluticasone Propionate Study Group. Clin Ther 20, 424-437.

46. Pauwels RA, Pedersen S, Busse WW, et al. (2003) Early intervention with budesonide in mild persistent asthma: a randomised, double-blind trial. Lancet 361, 1071-1076. 